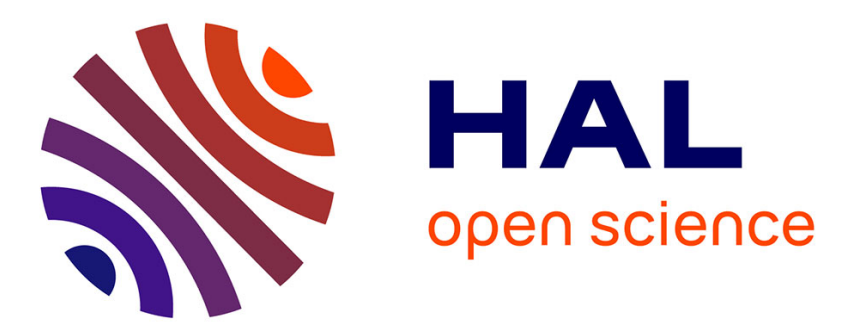

\title{
TWO-DIMENSIONAL PHASE TRANSITIONS AS STUDIED BY LEED AND AES : Xe AND Kr ADSORBED ON (0001) GRAPHITE
}

\author{
J. Suzanne, M. Bienfait
}

\section{- To cite this version:}

J. Suzanne, M. Bienfait. TWO-DIMENSIONAL PHASE TRANSITIONS AS STUDIED BY LEED AND AES : Xe AND Kr ADSORBED ON (0001) GRAPHITE. Journal de Physique Colloques, 1977, 38 (C4), pp.C4-93-C4-98. 10.1051/jphyscol:1977414 . jpa-00217130

HAL Id: jpa-00217130

https://hal.science/jpa-00217130

Submitted on 1 Jan 1977

HAL is a multi-disciplinary open access archive for the deposit and dissemination of scientific research documents, whether they are published or not. The documents may come from teaching and research institutions in France or abroad, or from public or private research centers.
L'archive ouverte pluridisciplinaire HAL, est destinée au dépôt et à la diffusion de documents scientifiques de niveau recherche, publiés ou non, émanant des établissements d'enseignement et de recherche français ou étrangers, des laboratoires publics ou privés. 


\title{
TWO-DIMENSIONAL PHASE TRANSITIONS AS STUDIED BY LEED AND AES : Xe AND Kr ADSORBED ON (0001) GRAPHITE
}

\author{
J. SUZANNE and M. BIENFAIT
}

Laboratoire des Mécanismes de la Croissance Cristalline, U.E.R. Scientifique de Luminy, 13288 Marseille Cedex 2, France

\begin{abstract}
Résumé. - La spectroscopie des électrons Auger, couplée à la diffraction des électrons lents, est une méthode puissante d'analyse des phases bidimensionnelles (2 D) adsorbées. C'est ce qui est montré, dans cet article de revue, sur l'exemple du xénon ou du krypton adsorbé sur le graphite (0001). Cette technique permet de préciser les propriétés thermodynamiques, structurales, vibrationnelles des phases $2 \mathrm{D}$ apparaissant dans la première couche atomique condensée de ces gaz rares. Elle permet également de mesurer la cinétique des transformations de phase. Parmi les grandeurs accessibles, on peut citer la chaleur latente et l'entropie de formation du cristal 2 D, l'énergie de liaison entre un atome de gaz rare et le substrat, les relations d'épitaxie entre l'adsorbat et l'adsorbant, ainsi que l'ordre de la réaction de transformation d'une phase en une autre. La transition analysée ici est la suivante : gaz $2 \mathrm{D} \rightleftarrows$ cristal $2 \mathrm{D}$. Enfin, on passe en revue les limitations de la méthode.
\end{abstract}

\begin{abstract}
This paper is a critical review of results obtained, by low energy electron diffraction and Auger electron spectroscopy, on the properties of two-dimensional phases occuring in the first layer of xenon or krypton adsorbed on (0001) graphite. It is shown that the LEED-Auger method is a suitable tool to analyse the thermodynamics, the structure, the thermal vibrations and the transition kinetics of $2 \mathrm{D}$ phases. One can measure the latent heat and the entropy of the $2 \mathrm{D}$ crystal formation, the binding energy between a rare gas atom and the graphite substrate. An outline of the atomic position of adsorbed atoms can also be given. At last, a mechanism of the transition $2 \mathrm{D}$ gas $\rightleftarrows 2 \mathrm{D}$ crystal can be taken out from the measurement of the kinetics of adsorption and desorption.
\end{abstract}

The discovery by Thomy and Duval [1-5] about ten years ago of the two-dimensional $(2 \mathrm{D})$ phase transitions : $2 \mathrm{D}$ gas $\rightleftarrows 2 \mathrm{D}$ liquid $\rightleftarrows 2 \mathrm{D}$ solid in the first atomic layer of simple molecules adsorbed on graphite was the starting point of numerous investigations of these new $2 \mathrm{D}$ phases. Of course, the adsorption volumetry method, which has been proved to be a powerful tool to study these phases, was developed extensively. But, at that time, every experimenter tried to use the latest technics in surface science to characterize the $2 \mathrm{D}$ phases and their transitions. In particular, in late 60 's, the low energy diffraction (LEED) and the Auger Electron Spectroscopy (AES) seemed to be an attractive method [6] to study surface phases. This method offers several advantages :

The adsorption can be achieved on a single crystal. The vapor pressure can be varied in the large $10^{-9}-10^{-4}$ torr range. Thus the $10^{-5}-100$ torr range of the volumetry method is extended toward the lower pressures.

A crystallochemical investigation of the substrate can be carried out: AES and LEED give information about the chemistry (cleanness) and the structure of the surface respectively.
But the main potentialities of the method lie in the measurement of several parameters characterizing the adsorbed phases. AES allows us to control the purity of the adsorbed layer and especially to obtain after calibration the surface coverage $\theta$. Hence two kinds of measurements can be performed. Firstly, the equilibrium coverage can be determined as a function of the pressure $p$ of the vapor phase and of the temperature $T$. An analysis of a $(p, \theta, T)$ diagram yields the thermodynamics of the adsorption [7]. Secondly, one can follow, at constant $T$, the variation of the coverage with a pressure change $\Delta p$. So, the kinetics of adsorption or desorption can be measured. Moreover LEED patterns give the structural properties of adsorbed phases. In favorable cases, the Debye Waller factor can be measured; it gives information about the mean vibrational properties of the two-dimensional crystals.

In order to check these potentialities, we have undertaken the study of the adsorption of xenon and krypton on (0001) graphite. Most of the results have already been published [8-18]. The pressure range of this study $\left(p<10^{-3}\right.$ torr) lies below the triple point of the $\mathrm{Xe}$ or $\mathrm{Kr}$ first layer. Thus we are only 
concerned with the simple $2 \mathrm{D}$ gas $\rightleftarrows 2 \mathrm{D}$ solid transition.

1. Thermodynamics, structure and vibrations. The experimental conditions have been described previously $[8,9,15]$. In brief, we introduce an air cleaved graphite crystal in an ion pumped UHV vessel with a combined four grid LEED/Auger system. The purity and the perfection of the (0001) graphite surface can be monitored before, during and after adsorption. The temperature of the crystal is regulated to better than $\pm 0.25 \mathrm{~K}$ and the xenon pressure is measured to a relative accuracy of better than $2 \%$. However, the absolute maximal uncertainty can be estimated for the surface temperature to $\pm 1 \mathrm{~K}$ and for the xenon pressure to $30-45 \%$ in the $10^{-7}$ torr range.

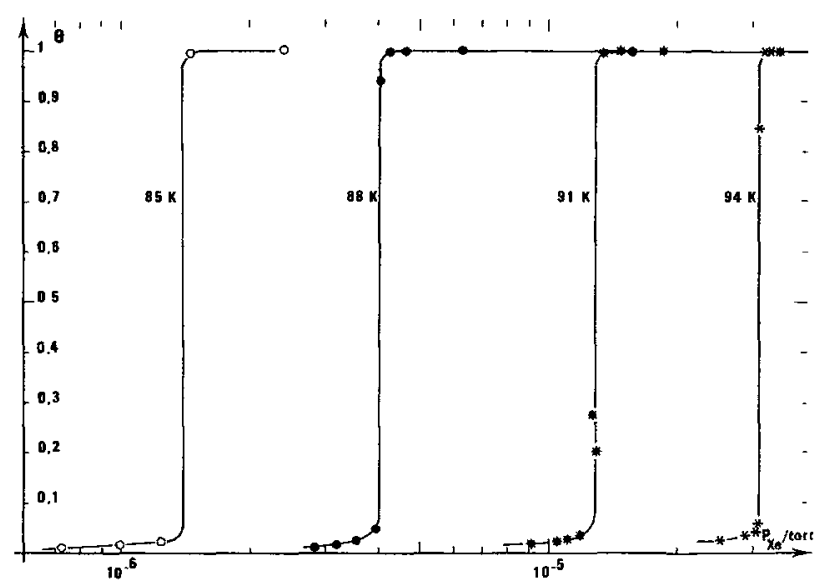

FIG. 1. - Adsorption isotherms of Xe on (0001) graphite. The step is well defined and corresponds to a two-dimensional gas $\rightleftarrows$ solid phase transition.

The peak to peak heights of the $40 \mathrm{eV}$ and of the $44 \mathrm{eV}$ transitions for $\mathrm{Xe}$ and $\mathrm{Kr}$ respectively are used to measure the surface coverage $\theta$. Typical adsorption isotherms for Xe are shown in figure 1. We observe first a very slow increase of the coverage, then a jump during the formation of the first layer and afterwards a plateau corresponding to the layer completion. The sensitivity is about $1 / 500$ th of an atomic layer, i.e. $\sim 10^{10}$ atoms. The curves are reversible and the results are reproducible. The stepwise shape of the adsorption isotherms means there is a first order phase transition between a low density phase ( $2 \mathrm{D}$ gas) and a condensed phase ( $2 \mathrm{D}$ solid). The structure of the $2 \mathrm{D}$ solid is deduced from the LEED pattern which exhibits a $\sqrt{3} \times \sqrt{3}$ superstructure when a Xe or $\mathrm{Kr}$ monolayer is condensed. A sketch of this structure is drawn in figure 2. However, the relative inaccuracy $(\sim 5 \%)$ of the spot positions in a standard LEED pattern $[8,15]$ yields the same uncertainty about the atom positions. As a matter of fact, other studies using THEED $[19,20]$ for Xe

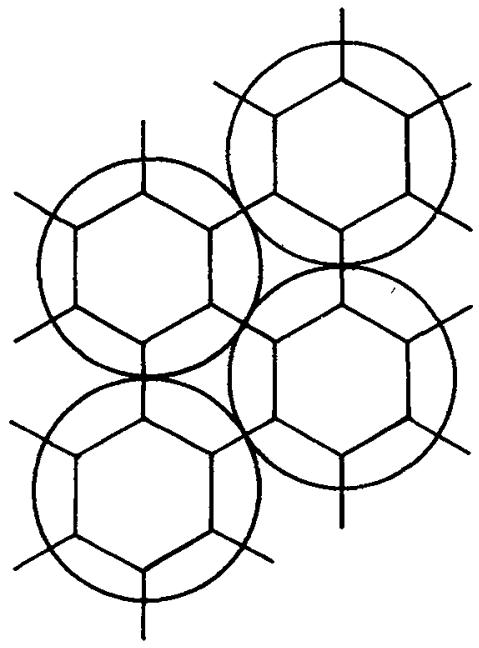

FIG. 2. - A sketch of the epitaxy of the first layer of $\mathrm{Kr}$ or Xe on (0001) graphite ( $O$ rare gas atoms, $\square$ graphite hexagons). In fact, $\mathrm{Xe}$ or $\mathrm{Kr}$ can be in or out of registry according to the pressure and temperature conditions.

and neutron diffraction [21] or improved LEED apparatus [22] for $\mathrm{Kr}$, have shown that rare gas atoms are not always located in the center of the hexagon well but can be out of registry depending on $p$ and $T$. Xenon seems to undergo a continuous transition from a non-localized to a localized structure whereas krypton has a more clear cut transition from a localized to a non-localized structure [23] when the pressure increases at constant temperature.

In order to obtain more thermodynamical information, we plot numerous adsorption isotherms in large temperature and pressure ranges $(73-100 \mathrm{~K}$, $10^{-9}-10^{-4}$ torr for $\mathrm{Xe} ; 56-67 \mathrm{~K}, 10^{-8}-10^{-5}$ torr for $\mathrm{Kr}$ ). The variation of the step pressure when temperature changes, must obey [24] a Clausius Clapeyron equation

$$
\frac{\mathrm{d}(\mathrm{Ln} p)}{\mathrm{d}(1 / T)}=-\frac{\Delta H}{R}
$$

where $\Delta H$ is the latent heat of transformation between the $2 \mathrm{D}$ crystal and the three dimensional vapor phase surrounding the crystal; $R$ is the perfect gas law constant.

We were able to check this equation within the range of $T$ and $p$ studied for $\mathrm{Xe}[9,10]$ and $\mathrm{Kr}[15]$. As a matter of fact, the relation between $\operatorname{Ln} p$ and $1 / T$ is perfectly linear. Results are drawn schematically in figure 3 where the equilibria $2 \mathrm{D}$ gas $\rightleftarrows 2 \mathrm{D}$ liquid, $2 \mathrm{D}$ liquid $\rightleftarrows 2 \mathrm{D}$ solid $[1,4,25$, $26]$, monolayer $\rightleftarrows$ double layer $[4,10,25,26]$ and the three-dimensional sublimation curve are also represented. The precise stability diagram can be found in reference [10] for Xe and reference [15] for Kr.

The slope of the equilibrium straight line gas $2 \mathrm{D} \rightleftarrows$ crystal $2 \mathrm{D}$ gives $\Delta H$. Its value for $\mathrm{Xe}$ and $\mathrm{Kr}$ 
TABLE I

Latent heat of the transition $3 \mathrm{D}$ gas $\rightleftarrows 2 \mathrm{D}$ crystal $\left(\Delta H_{2 \mathrm{D}}\right)$ obtained from various methods and latent heat of sublimation ( $3 \mathrm{D}$ gas $\rightleftarrows 3 \mathrm{D}$ crystal $-\Delta H_{3 \mathrm{D}}$ )

\begin{tabular}{|l|ccc|c|}
\hline & \multicolumn{3}{|c|}{$\Delta H_{2 \mathrm{D}}$ kcal mole } & \multirow{2}{*}{$\begin{array}{c}\Delta H_{3 \mathrm{D}} \\
\text { kcal mole }^{-1}\end{array}$} \\
\cline { 2 - 4 } $\mathrm{Xe}$ & AES & volumetry & calorimetry & $3.76[4]$ \\
\hline $\mathrm{Kr}$ & $3.5 \pm 0.1[9]$ & & $5.7 \pm 0.3[27]$ & $2.65[4]$ \\
\hline
\end{tabular}

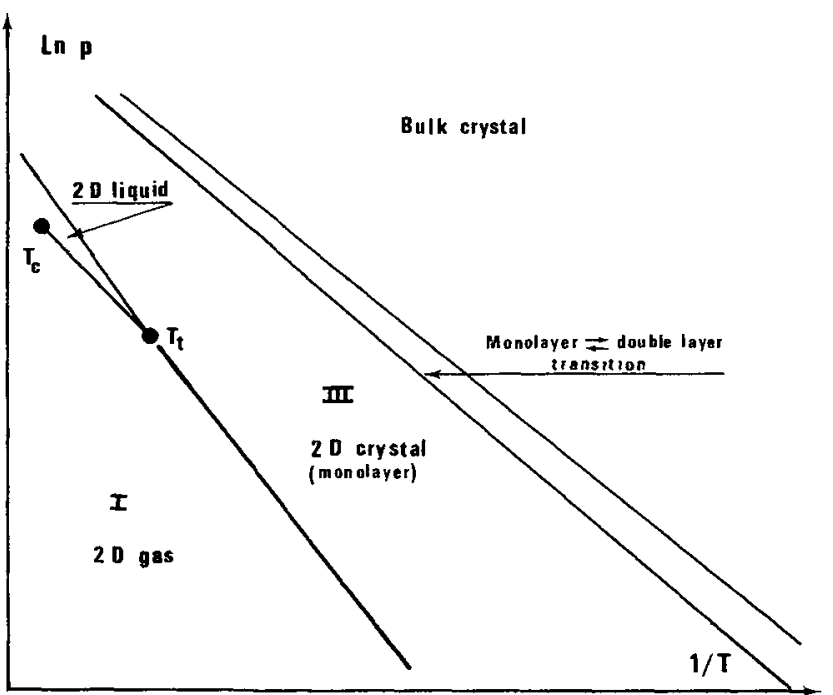

FIG. 3. - Schematic phase diagram for the adsorbed phases of $\mathrm{Xe}$ and $\mathrm{Kr}$ on (0001) graphite. $T_{\mathrm{c}}$ is the $2 \mathrm{D}$ critical temperature, $T_{\mathrm{t}}$ is the $2 \mathrm{D}$ triple point. The actual diagrams have been published in references [10] or [16] for Xe and in reference [15] for $\mathrm{Kr}$.

is listed in table I together with other values obtained from volumetric or calorimetric measurements and with the value of the threedimensional latent heat of sublimation. We see that $\mathrm{Xe}$ and $\mathrm{Kr}$ are more strongly bounded on graphite than in bulk crystal. This is the main reason why the adsorption of these rare gases occur in a layer-by-layer fashion.

From the intercept of the vapour pressure curve in the $\ln p=f(1 / T)$ representation, we can deduce the adsorption entropy $\Delta S$ which is the difference between the entropy of the first rare gas layer and the entropy of the $3 \mathrm{D}$ crystal $[9,15]$. The obtained value is very inaccurate but can give some information about the disorder in the $2 \mathrm{D}$ crystal. For instance, $\Delta S=-2 \pm 1$ cal mole $^{-1} \mathrm{~K}^{-1}$ for xenon.

A quick analysis [11] of adsorption isotherms shows that the entropy of the first layer is mainly due to the contribution of the vibrations. The negative value of the adsorption entropy implies that the vibrations of the adsorbed xenon layer are partly hindered with respect to the vibrations of the bulk crystal. This conclusion is in agreement with lattice dynamics calculations $[11,12]$.
Another information can be deduced from the latent heat of transition $\Delta H=H_{2 \mathrm{D}}^{\mathrm{c}}-H_{3 \mathrm{D}}^{\mathrm{g}}$ where $H_{2 \mathrm{D}}^{\mathrm{c}}$ is the enthalpy of the $2 \mathrm{D}$ crystal and $H_{3 \mathrm{D}}^{\mathrm{g}}$ the enthalpy of the vapour phase. In fact, $H_{2 \mathrm{D}}^{\mathrm{c}} \simeq u_{\perp}+u_{\mathscr{Z}}+u^{\mathrm{vib}}$ where $u_{\perp}$ is the perpendicular binding energy at $0 \mathrm{~K}$ of a rare gas atom on (0001) graphite, $u_{\sharp}$ the lateral binding energy and $u^{\text {vib }}$ the vibrational energy of atoms in the $2 \mathrm{D}$ phase. All these magnitudes $\left(\Delta H, H_{3 \mathrm{D}}^{\mathrm{g}}, u_{\mathscr{V}}, u^{\mathrm{vib}}\right)$, but $u_{\perp}$, are known $[9,15]$. So the perpendicular binding energy can be deduced. The obtained values : 3.6 and $2.6 \mathrm{kcal} \mathrm{mole}^{-1}$ for $\mathrm{Xe}$ and $\mathrm{Kr}$ respectively are in fair agreement with theoretical values.

At last, when the low energy electron scattering is nearly kinematic, i.e. : for xenon, it is possible to measure the Debye Waller factor of the superstructure spots intensity. This gives the mean square displacement of adsorbed xenon atoms. The measurements have been achieved for a direction close to the normal to the (0001) graphite plane [13]. The results show that the mean square displacements of atoms in a $2 \mathrm{D}$ xenon crystal is appreciably lower than those of the bulk xenon atoms. These findings agree with the conclusion about the entropy analysis and with lattice dynamics calculation $[13,14]$.

2. Adsorption and desorption kinetics. 2.1 ADSORPTION KINETICS. - Let us recall that we record the peak to peak height of a rare gas Auger transition, i.e. $\theta$ versus time when, at constant temperature, a supersaturation is established. Since we are interested in the $2 \mathrm{D}$ gas $\rightleftarrows 2 \mathrm{D}$ crystal transition in the first atomic layer, the supersaturation is defined with respect to the pressure $p$ of this transition $\left(\frac{\Delta p}{p}=\frac{p^{\prime}-p}{p}\right)$. The pressure $p^{\prime}$ is chosen so that the $2 \mathrm{D}$ crystal is stable (region III in Fig. 3). Experimental conditions are given in references [10] and [16]. Typical adsorption kinetics curves are plotted in figure 4 at $79 \mathrm{~K}$ for a few supersaturations. More than 30 such curves have been recorded for xenon between 74 and $76 \mathrm{~K}$ for different supersaturations $[16,18]$. The interpretation of these results allows to obtain three conclusions $[16,18]$ :

i) we do not measure an induction time before 


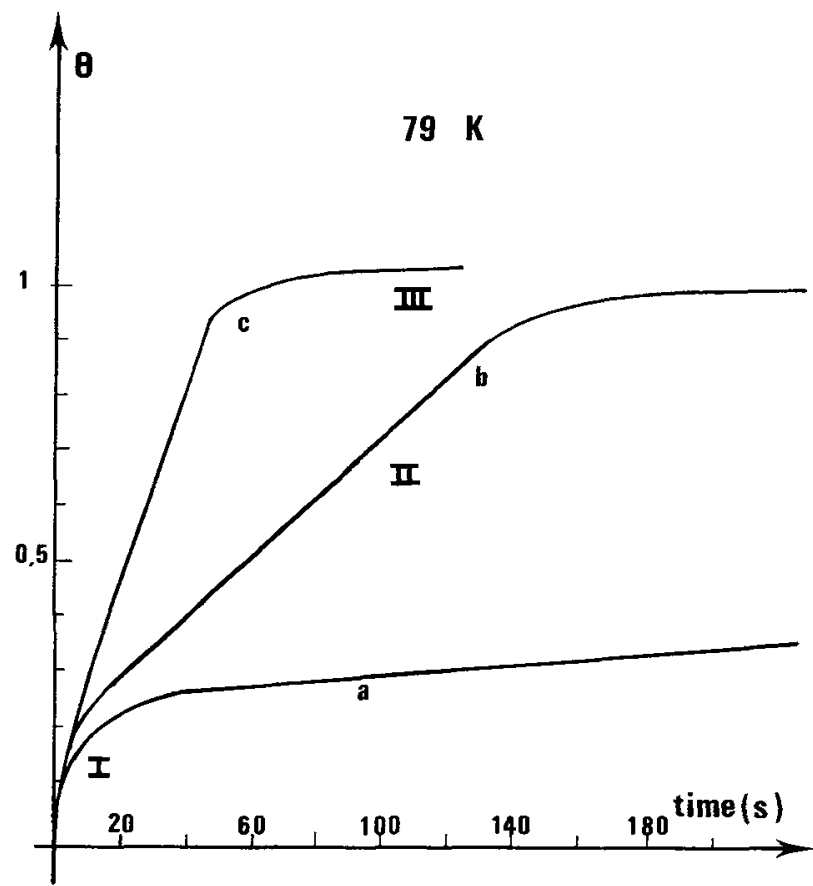

FIG. 4. - Adsorption kinetics of the first monolayer of xenon on (0001) graphite for different supersaturations

$$
\begin{aligned}
& \begin{array}{cccc} 
& \mathrm{a} & \mathrm{b} & \mathrm{c} \\
p^{\prime}\left(10^{-7} \text { torr }\right) & - & - & - \\
1,2 & 1,6 & 2,1
\end{array} \\
& p=1.15 \times 10^{-7} \text { torr }
\end{aligned}
$$

condensation which means there is little or no activation energy of $2 \mathrm{D}$ nucleation ;

ii) the coverage versus time curves shows three regimes: the first one (I) corresponds to the adsorption of the $2 \mathrm{D}$ gas, the second one (II) to the growth of $2 \mathrm{D}$ crystal in the presence of the $2 \mathrm{D}$ gas, and the third one (III) to the completion of the $2 \mathrm{D}$ crystal ;

iii) in regime II (coexistence of the $2 \mathrm{D}$ gas and the $2 \mathrm{D}$ crystal), the $\theta(t)$ curves are always straight lines; the rate of adsorption $\mathrm{d} \theta(\mathrm{II}) / \mathrm{d} t$ is independent of $\theta$. Thus the condensation follows a zero order kinetics. Moreover, this rate of adsorption is proportional to $p^{\prime} /(2 \pi m k T)^{1 / 2}$ where $m$ is the mass of xenon atom and $k$ the Boltzmann constant and $T$ the gas temperature : the condensation kinetics is determined by the incident flux only. This means that in regime II the xenon atoms condensing on the part of the surface covered with the $2 \mathrm{D}$ gas or on the other part covered with the $2 \mathrm{D}$ crystal, move on this surface and manage to settle in a growth site of a $2 \mathrm{D}$ crystal edge. In other words, atoms condense in a two steps process : $3 \mathrm{D}$ gas $\rightarrow 2 \mathrm{D}$ gas (in the first or in the second layer) $\rightarrow 2 \mathrm{D}$ crystal.

2.2 DESORPTION KINETICS. - In these experiments, the $2 \mathrm{D}$ crystal is formed at a given temperature and pressure. At $t=0$, the pressure is

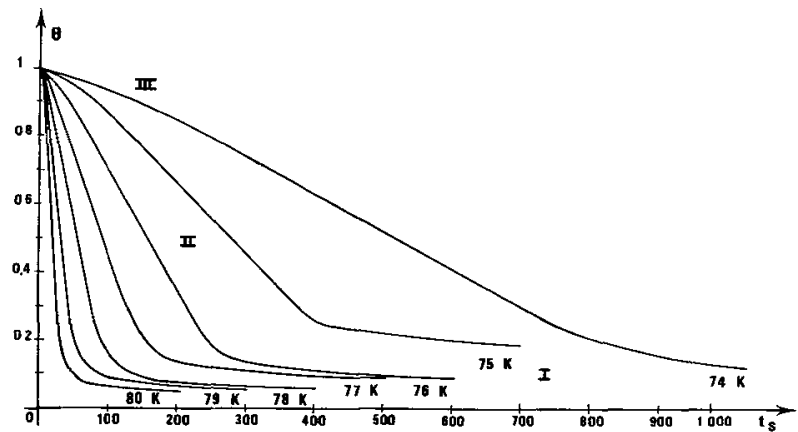

FIG. 5. - Isothermal desorption curves at different temperatures.

suddenly decreased [18] and a desorption curve is recorded. The results for different $T$ are plotted in figure 5 for xenon. Once again we recognize the three regimes I, II, III already described in thermodynamics and adsorption kinetics. We also see that in regime II the rate of desorption is independent of the coverage : desorption has, like adsorption, a zero order kinetics. Hence the mechanism of $2 \mathrm{D}$ crystal desorption is also a two steps process.

According to figure 5 , the rate of desorption in regime II depends strongly on the temperature. Plotting $\mathrm{d} \theta^{\mathrm{II}} / \mathrm{d} t$ versus $1 / T$ gives the activation energy of desorption [18]. Its value $6 \pm 0.4 \mathrm{kcal} \mathrm{mole}^{-1}$ agrees within the experimental error with the thermodynamical values of table $\mathrm{I}$.

3. Conclusion and discussion. - We have shown here that low energy electron diffraction and Auger electron spectroscopy are powerful methods to analyse the thermodynamics, the structural, the thermal vibrations and the transition kinetics of the two-dimensional adsorbed phases. The results obtained here on $\mathrm{Xe}$ and $\mathrm{Kr}$ have allowed us to complete the findings given by volumetric methods $[1-5,25]$. Now the stability domains of $2 \mathrm{D}$ adsorbed phases of $\mathrm{Xe}$ and $\mathrm{Kr}$ on (0001) graphite are well known in a very large pressure range $\left(10-10^{-9}\right.$ torr). These systems have become reference systems which are used to explore the possibilities of studying adsorption by other techniques like ellipsometry [28], neutron scattering $[21,29,30]$, THEED $[19,20]$, X-ray diffraction [31] or high resolution LEED [22].

Although LEED and AES are suitable tools to study adsorption, yet they still suffer some shortcomings. The pressure needs to be inferior to $10^{-4}$ torr to avoid electric break-downs. In this region, the absolute measurement of the pressure is less precise than at higher pressures as they are for instance used in volumetric studies. At the same time, it is hardly feasible to work under truly isothermal conditions. The gas impinging the cool surface comes from the vessel at room temperature. Only a quasi equilibrium is attained. Thus our experimental set-up is not suitable to determine 
thermodynamical quantities as latent heats of phase transitions with great precision. The accuracy is certainly poorer than the one obtained by volumetric method. But the LEED/Auger system does however allow measurements in a pressure region which is not accessible to the former method.

Additionally electron stimulated desorption can occur. This was observed for $\mathrm{Kr}$. This perturbation can generally be minimized by decreasing the incident electron beam. However, in some cases recently studied in the laboratory, like the adsorption of $\mathrm{NO}$ on graphite, it is rather difficult to prevent this effect.

Moreover, we sometimes observe the cracking by the electron beam of the molecules during the adsorption. For instance for $\mathrm{CH}_{4}$ or $\mathrm{C}_{2} \mathrm{H}_{6}$ on graphite, the substrate diffraction pattern disappears irreversibly in a few minutes whereas hydrogen is released as it is proved by mass spectroscopy. An amorphous layer of carbon is probably deposited on the surface.

At last, the standard LEED apparatus gives a mediocre precision $(\sim 5 \%)$ in the spots position. Thus it is difficult to know whether the adsorbed layer is localized or not as long as the misfit is inferior to about $5 \%$. This can however be achieved by improved LEED [22] or THEED [19, 20].

Although these shortcomings are serious, the comparison with the advantages of the LEED/Auger method listed in the introduction of this paper, allows to conclude that this method can be used as a complementary technique to the other methods to study adsorption. In some cases where these other methods do not work, LEED and AES are particulary suitable to obtain information on two-dimensional adsorbed phases.

\section{References}

[1] Thомy, A., Duval, X., In Adsorption et Croissance Cristalline (ed. CNRS) 196581

[2] ТномY, A., Duval, X., J. Chim. Phys. 66 (1969) 1966.

[3] Thомy, A., Duval, X., J. Chim. Phys. 67 (1970) 286.

[4] Tномy, A., Duval, X., J. Chim. Phys. 67 (1970) 1101.

[5] Thomy, A., Régnier, J., Menaucourt, J., Duval, X., $\boldsymbol{J}$. Cryst. Growth 13/14 (1972) 159.

[6] Lander, J. J., Morrison, J., Surf. Sci. 6 (1967) 1.

[7] Clark, A., The theory of adsorption and catalysis (Acad. Press, N.Y.) 1970.

[8] Suzanne, J., Coulomb, J. P., Bienfait, M., Surf. Sci. 40 (1973) 414.

[9] Suzanne, J., Coulomb, J. P., Bienfart, M., Surf. Sci. 44 (1974) 141.

[10] Suzanne, J., Coulomb, J. P., Bienfatt, M., Surf. Sci. 47 (1975) 204.

[11] Suzanne, J., Masri, P., Bienfart, M., Surf. Sci. 43 (1974) 441.

[12] Suzanne, J., Masri, P., Bienfatt, M., Japan J. Appl. Phys. Suppl. 2, Pt 2 (1974) 295.

[13] Coulomb, J. P., Suzanne, J., Bienfait, M., Masri, P., Solid State Commun. 15 (1974) 1585.

[14] Coulomb, J. P., MasRI, P., Solid State Commun. 15 (1974) 1623

[15] Kramer, H. M., Suzanne, J., Surf. Sci. 54 (1976) 659.

[16] Suzanne, J., Coulomb, J. P., Bienfait, M., J. Cryst Growth 31 (1975) 87
[17] Venables, J. A., Bienfait, M., Surf. Sci. 61 (1976) 667.

[18] Bienfait, M., Venables, J. A., Surf. Sci. 64 (1977) 425.

[19] Venables, J. A., Kramer, H. M., Price, G. L., Surf. Sci. 55 (1976) 373.

[20] Venables, J. A., Kramer, H. M., Price, G. L., Surf. Sci. 57 (1976) 782.

[21] Marti, C., Thorel, P., Croset, B., Le Vide, w- he published.

[22] Chinn, M. D., Farn, S. C., Jr., J. Vac. Sci. Technol. 14 (1977) 314

[23] Price, G. L., Venables, J. A., Surf. Sci. 59 (1976) 509

[24] LARHER, Y., J. Colloid Interface Sci. 37 (1971) 836.

[25] LarHer, Y., J. Chem. Soc. Faraday Trans. I70 (1974) 320.

[26] Putnam, F. A., Fort, T., J. Phys. Chem. 79 (1975) 459.

[27] Regnier, J., Rouquerol, J., Thomy, A., J. Chim. Phys. 72 (1975) 327

[28] Quentel, G., Rickard, J. M., Kern, R., Surf. Sci. 50 (1975) 343

[29] Thorel, P., Croset, B., Marti, C., Collomb, J. P., Proceeding of the Conf. on Neutron scattering. Gatlinburg, Tenn, USA 1 (1976) 85.

[30] Marti, C., Croset, B., Thorel, P., Coulomb, J. P. . Surf. Sci. in press.

[31] Brady, G. W., Fein, D. B., Steele, W. A., Phys. Rev. 15 (1977) 1120.

\section{DISCUSSION}

B. BODDENBERG. - Using a simple kinetic model you have explained the experimentally determined 0th order adsorption kinetics. How do you explain 0 th order desorption kinetics that has been observed?

J. SUZANNE. - In the case where you have first order phase change ( $2 \mathrm{D}$ solid $\rightarrow 2 \mathrm{D}$ gas) desorption kinetics are essentially the reverse phenomena of adsorption. In a microscopical point of view, an atom of the $2 \mathrm{D}$ crystal evaporates in a two steps process : $2 \mathrm{D}$ crystal $\rightarrow 2 \mathrm{D}$ gas $\rightarrow 3 \mathrm{D}$ gas. An atom going into the $2 \mathrm{D}$ gas phase comes from a repeatable step position, then it evaporates. So, each atom is in the same situation before evaporating. This point of view is confirmed by the value of the desorption energy very close to the energy of condensation of the first layer measured from our isotherms.

M. NIELSEN. - Do you think that NO molecules forms monolayers with parallel axies? I am interested in this system because it may have magnetic ordering. 
J. SUZANNE. - Isotherms measured by Matecki and Thomy showed two substeps in the formation of the first layer of NO adsorbed on graphite. The first step could correspond to molecules lying flat on the surface and the second step to molecules standing up on the surface with parallel axies. I agree, it may have magnetic ordering. We are going to study this system in I.L.L. Grenoble by neutron diffraction. 